\title{
Structure-Property Relationship in Terms of Dynamic Mechanical Properties of High Energy Radiation Treated Industrially Important Thermoplastic Elastomer Blend
}

\author{
Bhuwanesh Kumar Sharma1, Subhendu Ray Chowdhury ${ }^{2 *}$, Prakash Anna Mahanwar ${ }^{*}$, \\ Kuppa Siva Sankara Sarma ${ }^{2}$ \\ ${ }^{1}$ Institute of Chemical Technology, Matunga, Mumbai, India \\ ${ }^{2}$ Radiation Technology Development Division, Bhabha Atomic Research Centre, Trombay, Mumbai, India \\ Email: "pmahanwar@yahoo.com, ${ }^{*}$ rcsubhendu@gmail.com
}

Received 11 August 2015; accepted 8 September 2015; published 11 September 2015

Copyright (C 2015 by authors and Scientific Research Publishing Inc.

This work is licensed under the Creative Commons Attribution International License (CC BY). http://creativecommons.org/licenses/by/4.0/

\section{(c) (i) Open Access}

\begin{abstract}
A series of low-density polyethylene (LDPE)/ethylene propylene diene terpolymer (EPDM) blends with various compositions have been prepared by melt mixing followed by injection molding. These specimens are irradiated at 40, 80, 120 and $160 \mathrm{kGy}$ electron beam radiation. The gel content increases with increase in EPDM and as well as EB dose. Storage modulus (E') and loss modulus (E") are decreased with increase in EPDM content. Storage modulus continues to increase and loss modulus keeps on decreasing with radiation dose. Interestingly, damping property is found to be more for EPDM rich blends, which again decreases upon irradiation. Morphology of fractured surface of LDPE/EPDM shows that with increase in EPDM content, the size and depth of the cavity becomes larger and deeper indicating higher ductility. But, EB crosslinking makes the surface smoother and the smoothness keeps on increasing with increase in dose rendering stiffness to the samples.
\end{abstract}

Keywords

LDPE, EPDM, Electron Beam Crosslinking, DMA, SEM, Gel Content

\footnotetext{
${ }^{*}$ Corresponding authors.
}

How to cite this paper: Sharma, B.K., et al. (2015) Structure-Property Relationship in Terms of Dynamic Mechanical Properties of High Energy Radiation Treated Industrially Important Thermoplastic Elastomer Blend. Advances in Materials Physics and Chemistry, 5, 383-398. http://dx.doi.org/10.4236/ampc.2015.59039 


\section{Introduction}

Blending of a thermoplastic with an elastomer leading to a thermoplastic elastomer has become a practice for last forty years. Due to their advantages in processing of thermoplastic, with elastomer of excellent physical properties, it is gaining wide varieties of applications. This is a widely used technique nowadays in industries. There are various thermoplastics, which are unique for easy processing, availability, and low cost. Among the polyolefins, low density polyethylene (LDPE) and linear low density poly ethylene (LLDPE) are widely used plastics in the packaging and consumer industries because of their advantages like higher tensile strength, stress crack resistance, flexibility, thermal, chemical and excellent dielectric properties [1] [2] whereas EPDM elastomer exhibits high crosslinking ability, radiation resistance, thermal resistance, impact strength, flexibility and dynamic damping properties [3]. Thus, by judicial selection of properties of LDPE and EPDM scientists have made blends of above two, to get selected combination of properties [4] [5]. That is why; LDPE/EPDM blends have got their application in automobile, wire and cable insulation and construction applications [6] [7].

Mechanical, thermal, rheological and morphological properties of PE/EPDM blends have been investigated and reported [8]-[11]. M.M. Abdel-Aziz [12] is the first scientist to investigate the effect of gamma radiation on mechanical properties of LDPE/EPDM blends. Again, Mohammad E. has crosslinked the LDPE/EPDM blend by DCP (dicumyl peroxide) and studied mechanical, thermal, morphological and electrical properties [13]. Similar kinds of reports are available on HDPE/EPDM and EB crosslinked HDPE/EPDM [14] [15]. But, as per our knowledge there is no reported literature on the effect of electron beam irradiation on dynamic mechanical thermal analysis (DMA) of LDPE/EPDM system. Dynamic mechanical properties are important for some applications, where materials have to face high temperature environment along with high energy radiation exposure but has to maintain mechanical performance to retain them useful. In this environment LDPE/EPDM may be a suitable candidate for medium radiation dose and temperature range. On the other hand, EB irradiation has become an important process in the development of new materials with improved technical properties. The process is neat, residue free, selective, flexible, uniform, easily controllable, economical and most effective in crosslinking of polymers in large scale. This process has been effectively utilized in the power cable industry for crosslinking of polyolefins [16]. Recently high-energy electron beam radiation (EBR) has been used in the dynamic vulcanization of polymer blends leading to thermoplastic elastomer vulcanizations (TPV) [17]. High energy electron beam irradiation of polymers leads to formation of macro-radicals which react with each other to form inter and intramolecular crosslinking leading to a three dimensional network structure [18] [19]. If the dose is higher i.e. free radical production in extensive, then chain scission may occur, which will lead to degradation of polymers [20]. The objective of the work is to investigate the effect of radiation dose and blend composition on the gel content (crosslinking), dynamic mechanical properties, phase morphology and to establish their correlations.

\section{Experimental}

LDPE (MFI $4 \mathrm{gm} / 10 \mathrm{~min}$, density of $0.922 \mathrm{gm} / \mathrm{cc}$ ) in form of pellets has been supplied by Reliance Petrochemicals. EPDM (pellet form, Mooney viscosity, ML1+4 at $125^{\circ} \mathrm{C} 20$, NORDEL IP 4520 , ethylene content $=50 \%$ with $4.9 \%$ of ENB, MFI $10 \mathrm{gm} / 10 \mathrm{~min}$ and density of $0.88 \mathrm{gm} / \mathrm{cc}$ ) is supplied by Dow chemical. These are used to prepare blends. LDPE is blended with EPDM in different compositions using twin screw extruder with the temperature profile of $120^{\circ} \mathrm{C}: 140^{\circ} \mathrm{C}: 160^{\circ} \mathrm{C}: 180^{\circ} \mathrm{C}$ at $80 \mathrm{rpm}$ without any crosslinker. Both components are mixed in various weight proportions to prepare blends (100/0, 70/30, 50/50, 30/70, 0/100). For study purpose dumble shaped samples are prepared by injection molding at $180^{\circ} \mathrm{C}$. The codes of the samples are provided in Table 1. In the sample code "L" stands for LDPE and "E" stands for EPDM. The injection molded specimens

Table 1. Blend compositions.

\begin{tabular}{cccccc}
\hline Samples & 1 & 2 & 3 & 4 & 5 \\
\hline LDPE & 100 & 70 & 50 & 30 & 0 \\
EPDM & 0 & 30 & 50 & 70 & 100 \\
Sample code & L 100 & LE73 & LE55 & LE37 & E 100 \\
\hline
\end{tabular}

“L” stands for LDPE and “E” stands for EPDM. 
are irradiated by high energy electron beam in an inert environment using $2 \mathrm{MeV}, 20 \mathrm{~kW}$ electron beam accelerator (Model ILU-6) under forced air cooling at a radiation dose of 40, 80, 120 and 160 kGy (kilo Grey). Only one side of the sample is exposed to irradiation, as the thickness of the sheet is $2 \mathrm{~mm}$, which is thin enough for penetration of the electron beam of $2 \mathrm{MeV}$ energy. The distance of the sample from the scan horn is $20 \mathrm{~cm}$ and the conveyer speed is set at $0.94 \mathrm{~m} / \mathrm{min}$. The dose rate is $10 \mathrm{kGy} /$ pass and beam current is $1 \mathrm{~mA}$.

\section{Characterization}

Gel fractions are measured by solvent extraction technique using xylene as solvent. The samples are extracted in hot Xylene for $48 \mathrm{hrs}$ at $110^{\circ} \mathrm{C}$. Extracted samples are dried in a vacuum oven at $80^{\circ} \mathrm{C}$ till constant weight. The gel content (\% gel fraction) is determined using the following formula:

$$
\text { (\%) Gel content }=\frac{\text { Weight after extraction }}{\text { Weight before extraction }} \times 100
$$

The FTIR spectra of both unirradiated and irradiated samples (2 mm thick) have been recorded on a BrukerAlpha's Platinum ATR model. Samples are characterized on Attenuated total reflection (ATR) mode in wave number ranging from $500-4000 \mathrm{~cm}^{-1}$. Dynamic mechanical thermal analysis (or Dynamic mechanical analysis) is carried out for LDPE-EPDM blends to determine the viscoelastic properties of the samples. The test is performed in tension mode using EPLEXOR $150 \mathrm{~N}$ (Gabo Qualimeter) instrument. The temperature range is -150 to $80^{\circ} \mathrm{C}$ with a heating rate $3^{\circ} \mathrm{C} / \mathrm{min}$. The dimension of test samples is $20 \mathrm{~mm} \times 6 \mathrm{~mm} \times 2 \mathrm{~mm}$. The Analysis is investigated on temperature sweep mode at constant frequency of $1 \mathrm{~Hz}$ to find out storage modulus (E'), loss modulus (E”) and loss tangent $(\tan \delta)$ for unirradiated and irradiated blends. The samples of LDPE/EPDM blends fractured in liquid nitrogen are characterized by SEM (scanning electron microscopy) using JEOL, JSM-5400 model. To increase the conductivity, fractured surfaces are gold sputtered before investigation under the scanning electron microscope.

\section{Results and Discussion}

The susceptibility of LDPE, EPDM and various LDPE/EPDM blends, towards radiation induced cross-linking process, in absence of crosslinker, is estimated from the gel fraction determination. Results are presented in Figure 1. Higher is the gel content greater will be the amount of crosslinking, as gel content is the measurement of amount of crosslinking [21] [22]. There is no gel formation observed for control systems. It is clear from the Figure 1 that neat LDPE shows 50.43\%, 71.94\%, 78.01\% and 83.01\% gel fraction at 40, 80, 120 and $160 \mathrm{kGy}$ EB doses respectively. On the other hand, for pure EPDM, the gel contents are $76.81 \%, 87.69 \%, 92.38 \%$ and $86.32 \%$ at the same doses respectively. Thus, it is revealed that the gel content i.e. crosslinking ability is increased steadily with increase in radiation doses up to $120 \mathrm{kGy}$ for both polymers (LDPE and EPDM). That

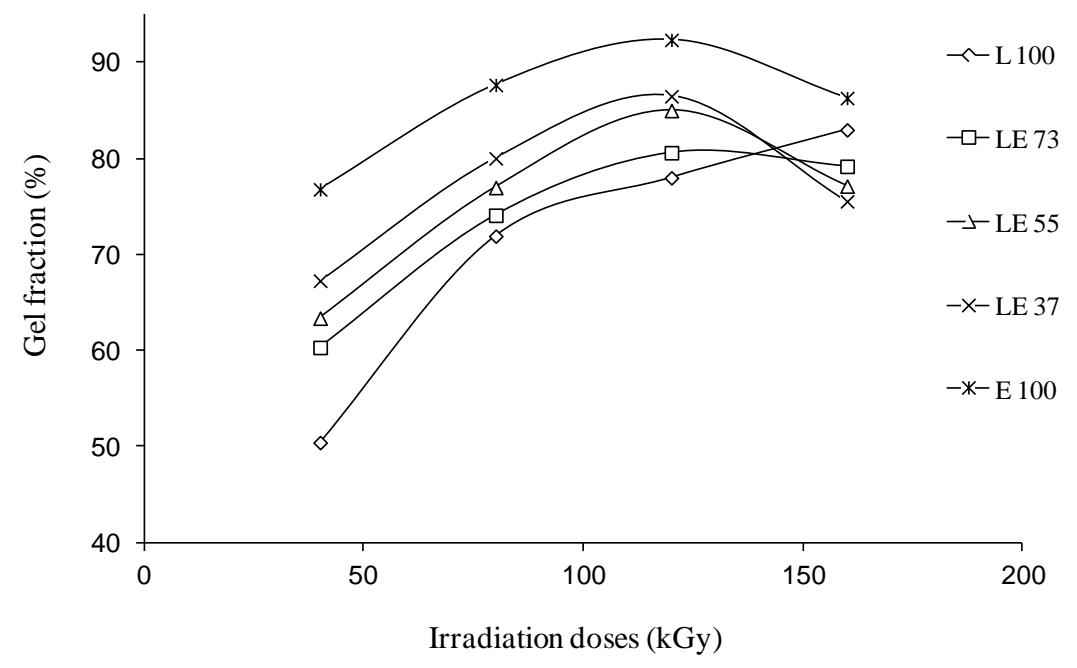

Figure 1. Variation of gel fraction with blend composition and electron beam irradiation dose. 
proves up to $120 \mathrm{kGy}$, in both the polymers, crosslinking process dominates over the chain scission process. Similar increasing trend is noticed even at $160 \mathrm{kGy}$ for LDPE. This is due to it's higher crystallinity and lower speed of crosslinking. Interestingly, the gel content of EPDM is decreased at $160 \mathrm{kGy}$. At this higher dose EPDM is degraded. From the figures it is again obvious that, at a certain dose, EPDM shows higher gel fraction than LDPE and that is true for all studied doses. That is due to higher crosslinking ability of EPDM than LDPE. The crosslinking ability of EPDM is more due to higher amorphousness and molecular structure of EPDM [23].

So, it is expected that with increase in EPDM content in blends, gel fraction would keep on increasing. That is the finding throughout the experiments, which has been discussed later. Interestingly, as in LDPE and EPDM, the gel contents of LDPE/EPDM blends are also in increasing trend with increase in irradiation dose up to 120 kGy. But at $160 \mathrm{kGy}$, all LDPE/EPDM blends degrade showing reduced gel fractions. Chain scission is initiated in blends due to presence of EPDM component. In LE 73 blends the percentage of gel fraction are observed to be $60.34 \%, 74.11 \%, 80.63 \%$ and $79.21 \%$ for different electron beam doses (40, 80, 120 and $160 \mathrm{kGy})$. In LE55 blends, the gel fractions are higher than that of LE 73 blends due to greater amount of EPDM content in blends. The increased gel content in LE 55 blends are 63.39\%, 77.00\%, 85.02\% and 77.15\% at 40, 80, 120 and $160 \mathrm{kGy}$. It is again seen that LE 37 blend shows higher degree of change in gel fraction compared to LE 73 and LE 55 blends. The values of gel fractions for LE37 blends are $67.29 \%, 80.04 \%, 86.51 \%$ and $75.56 \%$ at the above mentioned doses.

FTIR spectra of LDPE, EPDM and various unirradiated and irradiated LDPE/EPDM blends are taken and represented in Figure 2. As during crosslinking new -C-C- bonds are formed but LDPE and EPDM possess

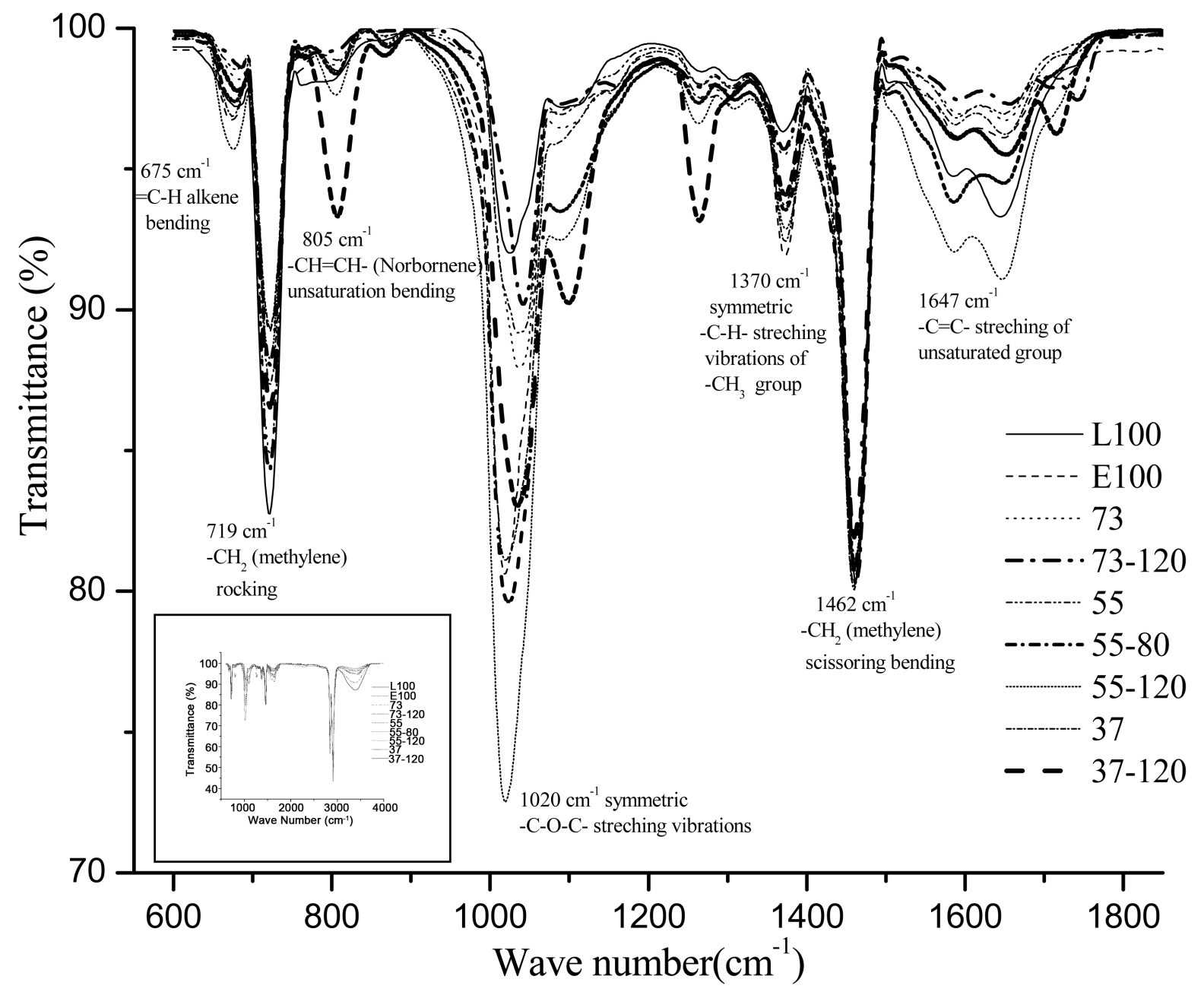

Figure 2. FTIR of unirradiated and irradiated LDPE/EPDM blends. 
plenty of C-C bonds, so expectedly no new peak corresponding to -C-C- bond formation will appear rather the intensity corresponding to various modes of C-C bond vibration will alter, producing signal of radiation crosslinking. However, new bonds corresponding to chain scission may appear. A prominent strong peak appears at $719 \mathrm{~cm}^{-1}$ (Figure 2), which is assigned as $-\mathrm{CH}_{2}$ rocking vibration peak [3]. This peak is present both in LDPE and EPDM. For LDPE, the transmittance is found least that means the absorbance is highest due to presence of large number of $-\mathrm{CH}_{2}$ groups. Interestingly, it is noticed that upon crosslinking absorbance intensity of $-\mathrm{CH}_{2}$ rocking vibration is increased due to formation of new -C-C- bonds. That is reflected for all three blends and the effect is highest in LE37, due to highest amount of crosslinking in EPDM phase (as shown in gel content, Figure 1). Similar effect is observed at 2840 and $2916 \mathrm{~cm}^{-1}$, which are ascribed to $-\mathrm{CH}_{2}$ symmetric and asymmetric stretching [24]. Again a high intensity peak appears at $1370 \mathrm{~cm}^{-1}$, which is due to $-\mathrm{C}-\mathrm{H}$ symmetric stretching of $\mathrm{CH}_{3}$ group [24]. This absorbance is least for LDPE and highest for EPDM due to different degree of freedom in crystalline and amorphous phase of former and later respectively. Upon cross linking transmittance corresponding to this peak of all blends become more, due to less freedom of $\mathrm{CH}_{3}$ group in a compact crosslinked network structure and the difference of the transmittance before and after crosslinking i.e. reduction of absorbance depends on blend composition and gel content, i.e. degree of crosslinking. On crosslinking same trend is observed for peak $1462 \mathrm{~cm}^{-1}$ which is the characteristics of $-\mathrm{CH}_{2}$ scissoring vibration. Interestingly, very strong peaks appear at $1020 \mathrm{~cm}^{-1}$ and $1274 \mathrm{~cm}^{-1}$ ascribed for symmetric and asymmetric stretching of -C-O-C-[3]. After crosslinking absorbance of these two peaks are reduced due to cleavage of - $\mathrm{C}-\mathrm{O}-\mathrm{C}$ - bond by high energy radiation and formation of new $-\mathrm{C}-\mathrm{C}$ - bonds. EB irradiation occurs in inert environment, thus the above oxides must have formed during thermal processing of polymers. However, it is beneficial that during irradiation these previously formed oxides are broken though the effect in LE 55 is not convincing.

Absorbance at $675 \mathrm{~cm}^{-1}$ and $1647 \mathrm{~cm}^{-1}$, which are due to stretching of $-\mathrm{C}=\mathrm{C}$ - bond, are increased after irradiation [24]. This is the evidence of chain scission during irradiation. Upon irradiation, the increase in absorbance intensity is found highest for LE55, leaving LE 73 and LE37 very very less. It is again noticed that after long time exposure to radiation (120 kGy) still peak of norbornene unsaturation of EPDM occurs at $805 \mathrm{~cm}^{-1}$ [25] for all blends. Thus, though norbornene double bond contributes to radiation crosslinking i.e. property development, but the contribution is much much lesser than $-\mathrm{C}-\mathrm{H}$ bond's contribution because of its small quantity (4.9\% of ENB) and incomplete crosslinking. The schematic diagram of crosslinking and chain scission based on the FTIR spectra is represented in Figure 3(a) and Figure 3(b).

The dynamic mechanical properties (storage modulus, loss modulus and $\tan \delta$ ) of pure LDPE, EPDM and LDPE/EPDM blends before irradiation are reported in Figures 4(a)-(c). To understand the change quantitively storage modulus, loss modulus as well as transition temperatures are tabulated in Table 2. The storage modulus (E') for LDPE at sub ambient temperature of $-140^{\circ} \mathrm{C}$ is $3780 \mathrm{MPa}$, which drastically reduces to $2120 \mathrm{MPa}$ at $-75^{\circ} \mathrm{C}$. This further reduces to around $327 \mathrm{MPa}$ at $25^{\circ} \mathrm{C}$ prevalent for semicrystalline polymer. Thus, it is obvious that the storage modulus exhibits two step reduction; one near the $\gamma$ transition region and other near the $\beta$ transition region. (The details on relaxation are discussed later in this section). Neat EPDM also exhibit similarly two-step reduction in dynamic (storage) modulus [Table 2 and Figure $4(\mathrm{a})$ ]. At $-140^{\circ} \mathrm{C}$ the elastic (storage) modulus of EPDM is $1720 \mathrm{MPa}$, which reduces to 926 and $9 \mathrm{MPa}$ at $-75^{\circ} \mathrm{C}$ and $25^{\circ} \mathrm{C}$ respectively.

The storage moduli of all blends are decreased with temperature following similar fashion as LDPE and EPDM due to increase in flexibility. Again, it is interesting to note that the modulus of neat EPDM is significantly lower than that of neat LDPE in the whole range of temperature studied. This is due to the greater stiffness originated from compact organized crystalline structure of LDPE. The blends, on the other hand, exhibit storage moduli in between the two neat polymers in the whole temperature range. Figure 4(a) shows that the storage moduli of blends decrease with the increase in EPDM contents. From the table it is seen that, at $-140^{\circ} \mathrm{C}$, the storage modulus of blends decreases with increase of EPDM content in blends (from LE73 to LE37). Storage modulus is a measurement of rigidity and stiffness of the samples [26]. If EPDM content increases in blend, stiffness and rigidity due to amorphous nature of EPDM decreases.

The alterations of dynamic mechanical properties of neat polymers and blends, with radiation dose and temperature are illustrated in Figures 5(a)-(c), Figures 6(a)-(c) and Figures 7(a)-(c) for LE73, LE55 and LE37 respectively.

Upon irradiation storage modulus of LE73 increases, which continues to increase with dose up to $120 \mathrm{kGy}$ (Figure 5(a)). For irradiated samples, the trend of decrease of storage modulus with temperature is similar as unirradiated one (Table 2). It is noticed that in gel content analysis that crosslinked network is formed upon ir- 
Electron beam (EB) crosslinking and chain scission in low density Polyethylene (LDPE)
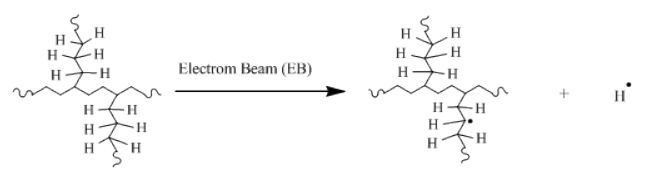

Low density polyethylene (LDPE, $R$

LDPE free radical $R_{1}^{*} \quad$ Hydrogen Free Radical
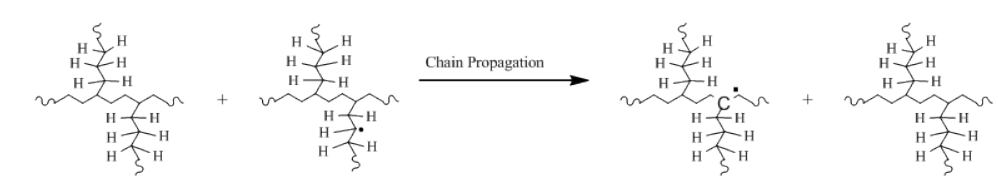

Another Chain (LDPE, R)

$$
\text { LDPE free radical } R_{1}^{*}
$$

$$
\text { LDPE free radical } R_{2} \cdot
$$

$\operatorname{LDPE}(\mathrm{R})$

All -C-H bond in LDPE can form LDPEfree radicals by direct electron beam (EB) radiation or by chain propagation reaction. All LDPE free radicals $\left(\mathrm{R}_{1}{ }^{\circ}, \mathrm{R}_{2}, \ldots \ldots ..\right)$ can be

represented by $\mathrm{R}^{\circ}$. These all macromolecular free radicals $\left(\mathrm{R}^{\circ}\right)$ can either form three dimentional network through -C-C- bond(chain crosslinking) or lead to chain scission.

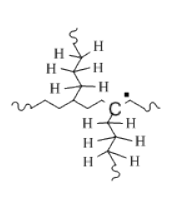

LDPE free radical $\mathrm{R}^{*}$

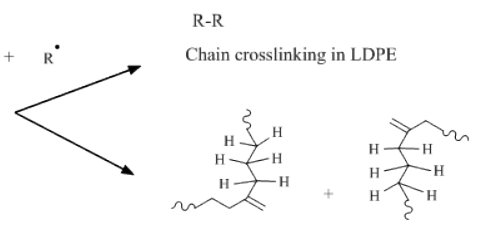

Chain scission in LDPE

(a)

Electron beam chain crosslinking and scission in Ethylene Propylene Diene Elastomer (EPDM)

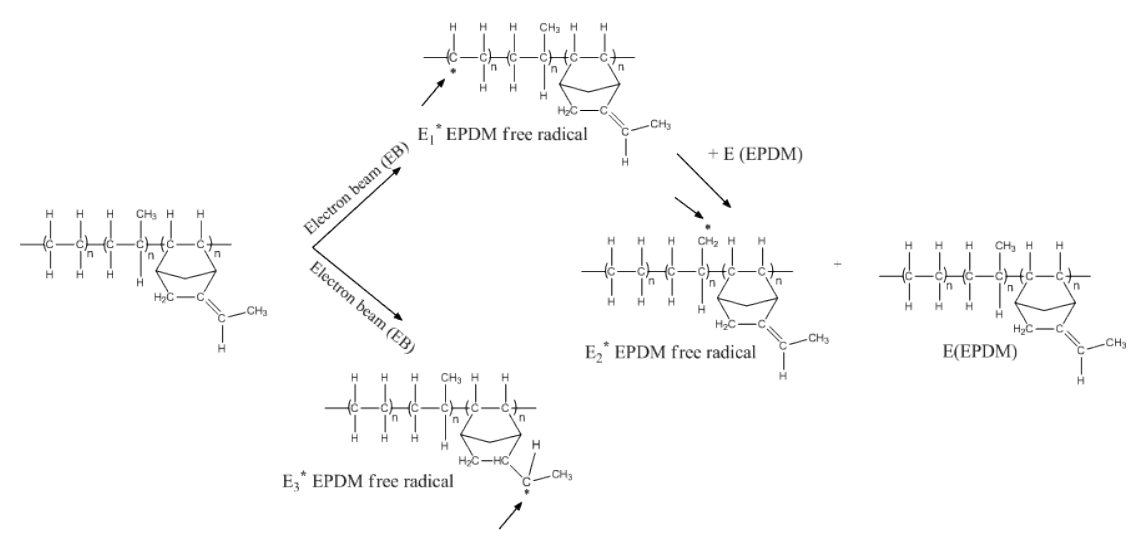

Similarly, all -C-H bond in EPDM can generate EPDM free radicals $\left(\mathrm{E}_{1}{ }^{*}, \mathrm{E}_{2}{ }^{*} \mathrm{E}_{3}{ }^{*} \ldots.\right)$ by direct electron beam irradiation or chain propagation reaction. We can represent all free radicals by $\mathrm{E}^{*}$ which can either form 3D network by -C-C- bond or undergo chain scission.

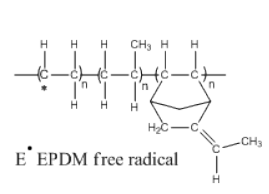

Crosslinking between LDPE and EPDM

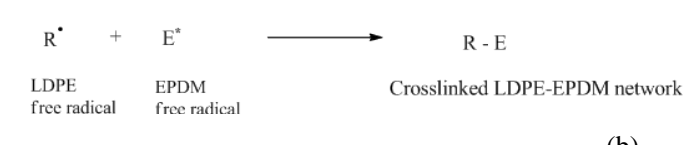

E- E 3D crosslink network in EPDM

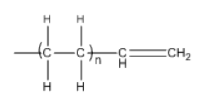
Chain Scission

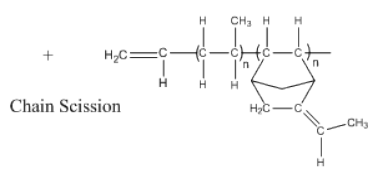

(b)

Figure 3. (a) Schematic diagram of radiation crosslinking and degradation of LDPE; (b) schematic diagram of radiation crosslinking and degradation of EPDM and LDPE/EPDM Interphase crosslinking. 


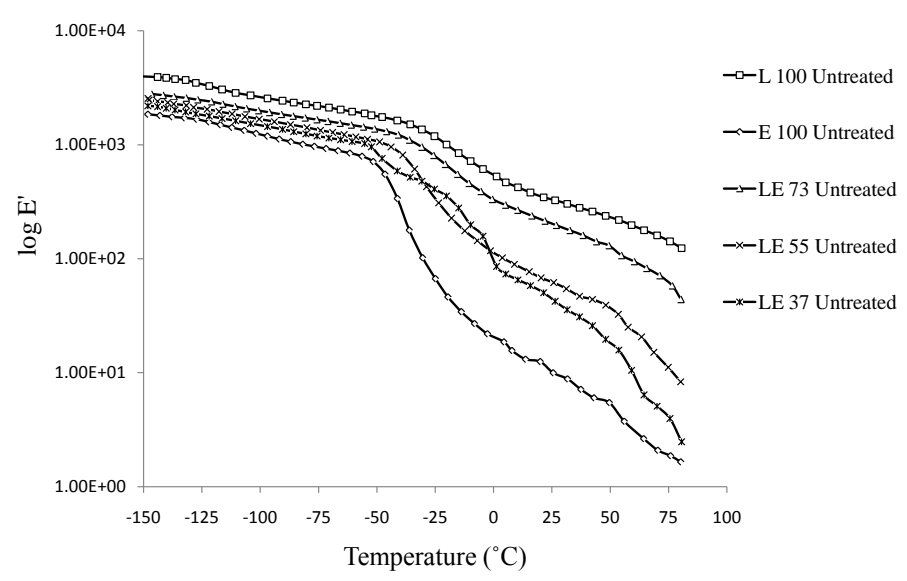

(a)

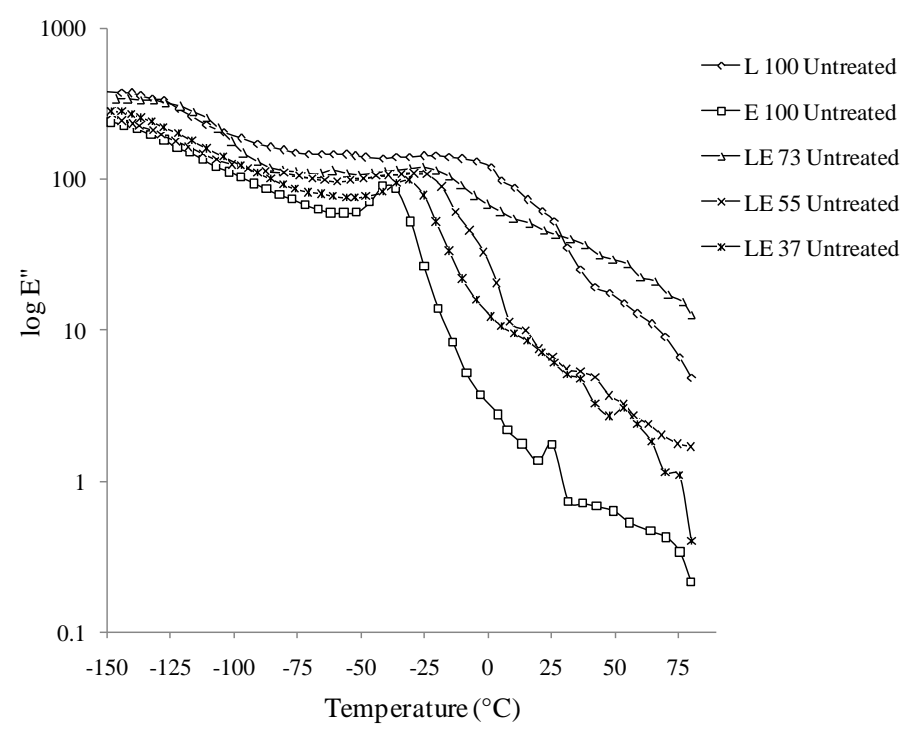

(b)

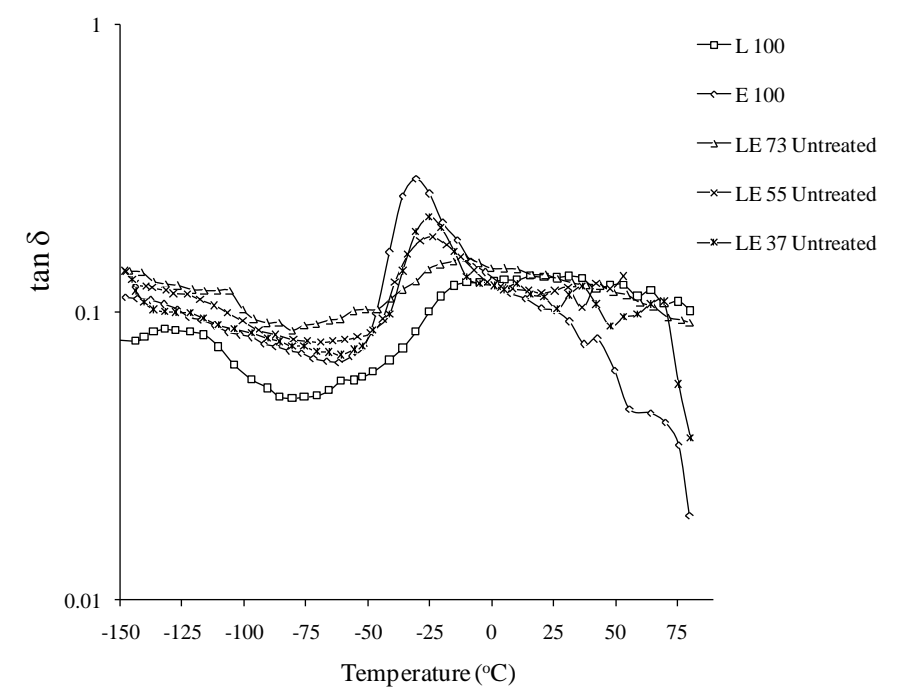

(c)

Figure 4. (a) Variation of storage modulus of blends with composition and temperature; (b) variation of loss modulus of blends with composition and temperature; (c) variation of $\tan \delta$ of blends with composition and temperature. 


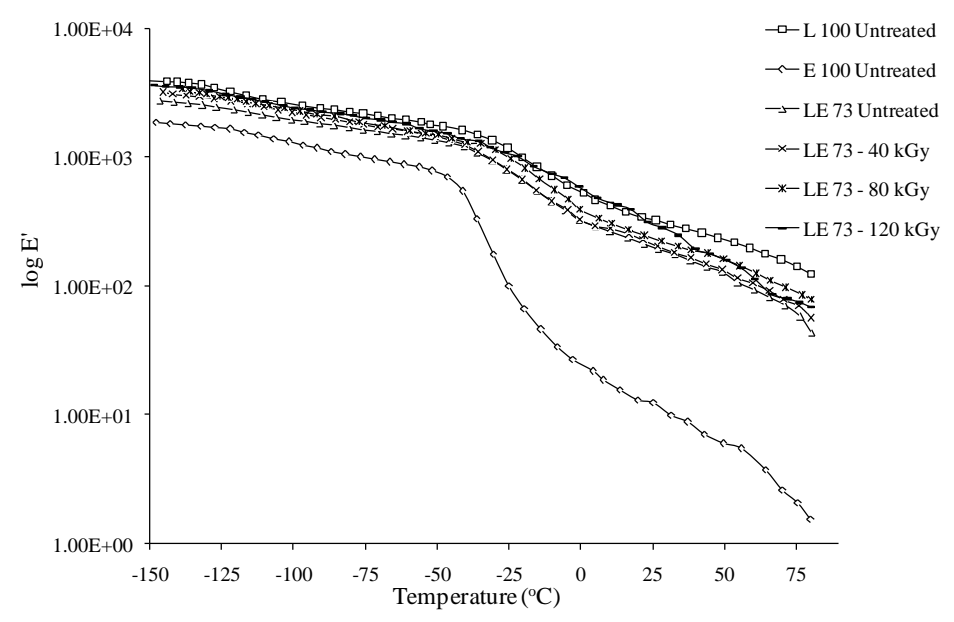

(a)

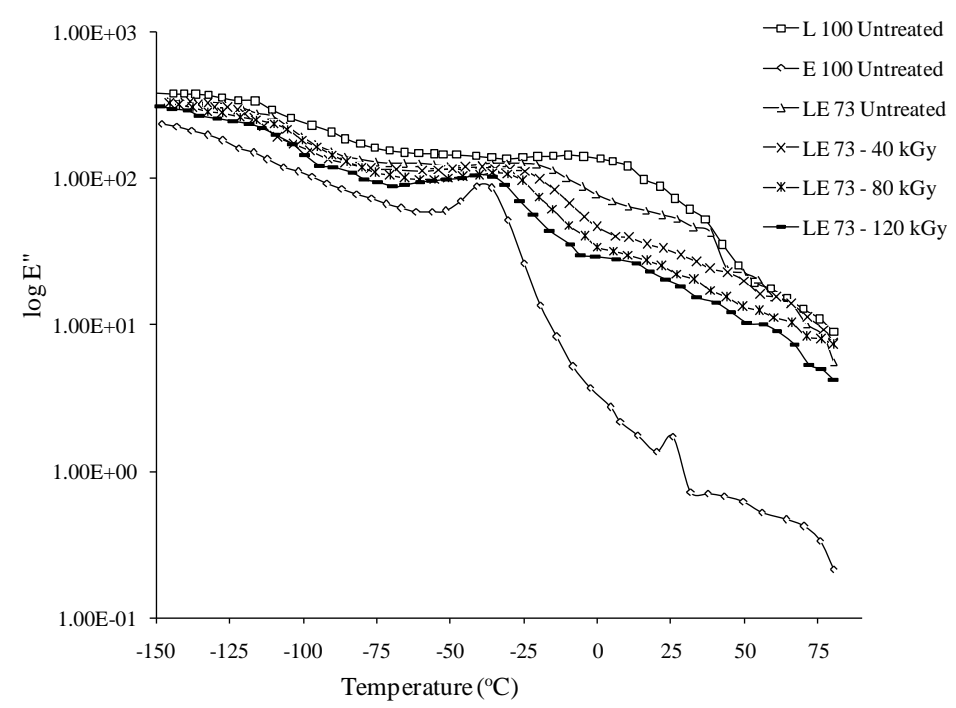

(b)

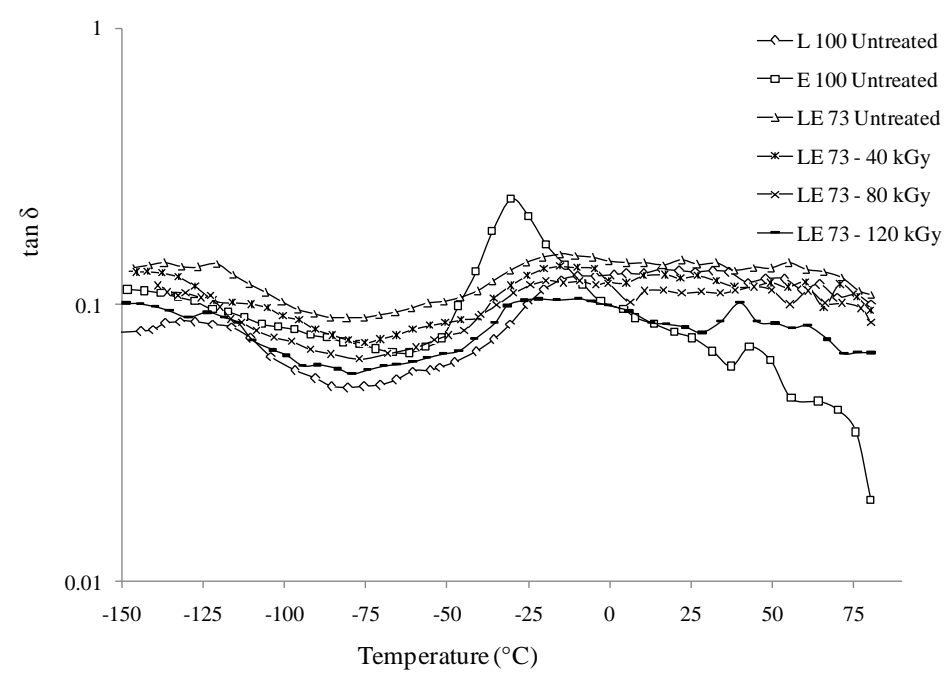

(c)

Figure 5. Variation in dynamic mechanical properties of LE73 blends with temperature and radiation dose (a) variation in storage modulus (b) variation in loss modulus (c) variation in $\tan \delta$. 


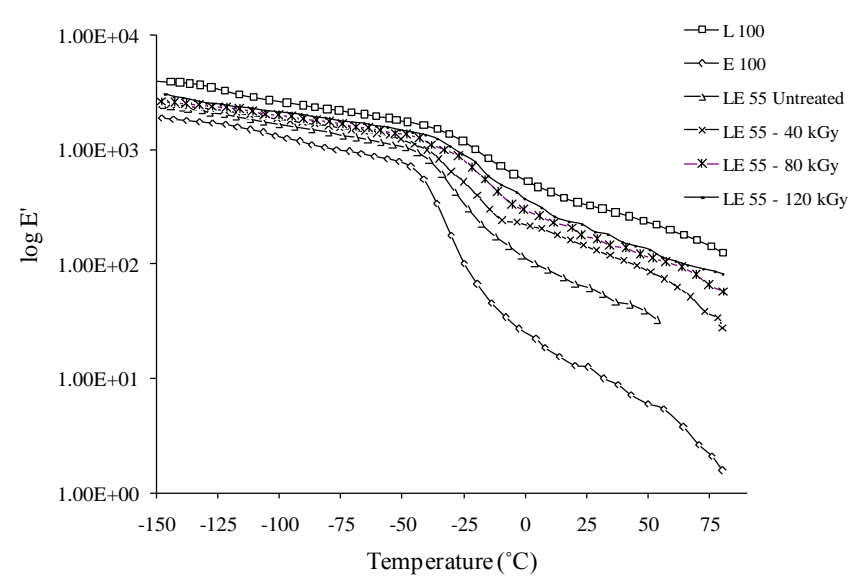

(a)

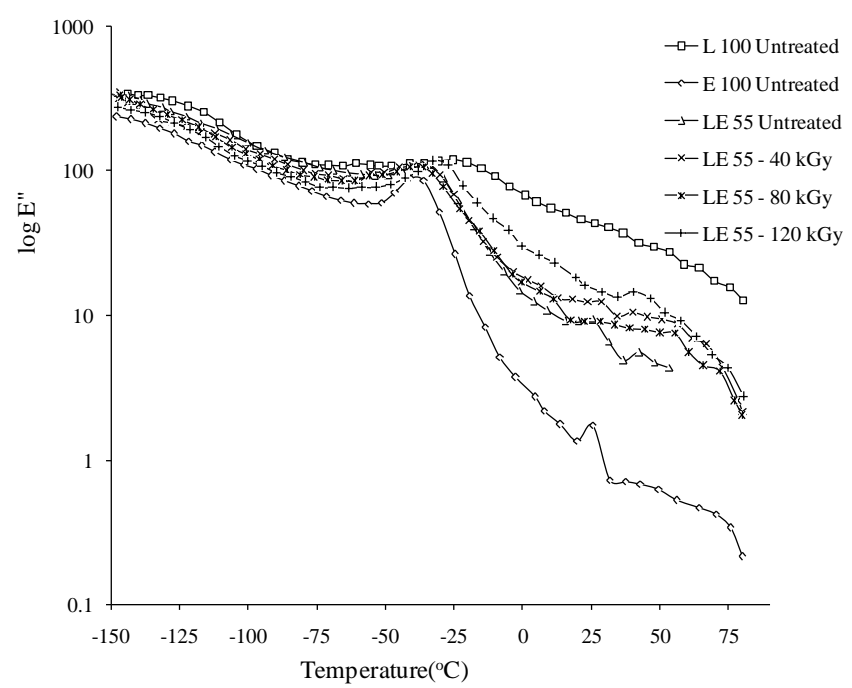

(b)

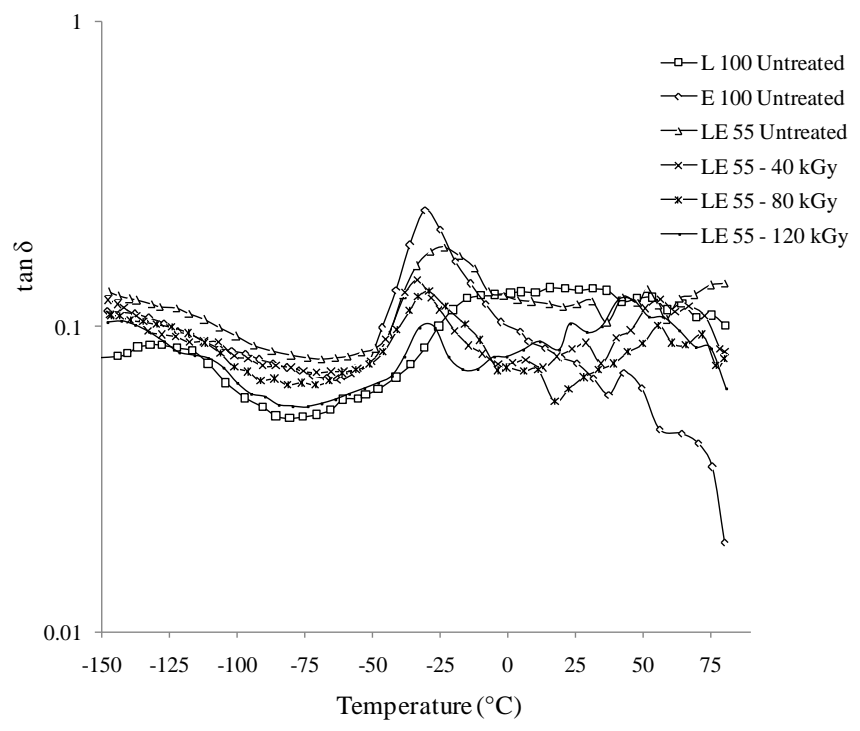

(c)

Figure 6. Variation in dynamic mechanical properties of LE55 blends with temperature and radiation dose (a) variation in storage modulus (b) variation in loss modulus (c) variation in $\tan \delta$. 


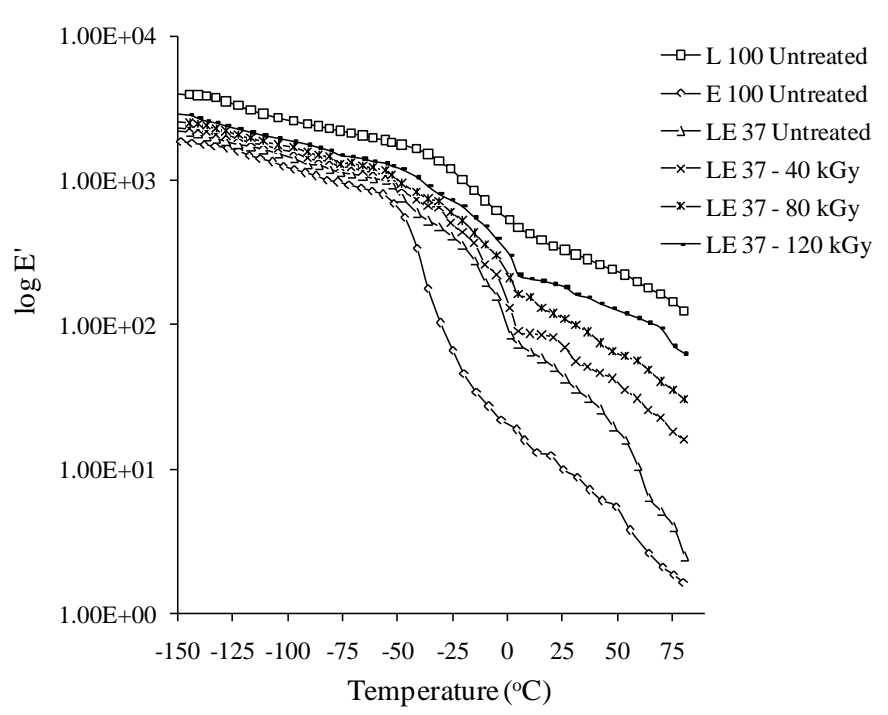

(a)

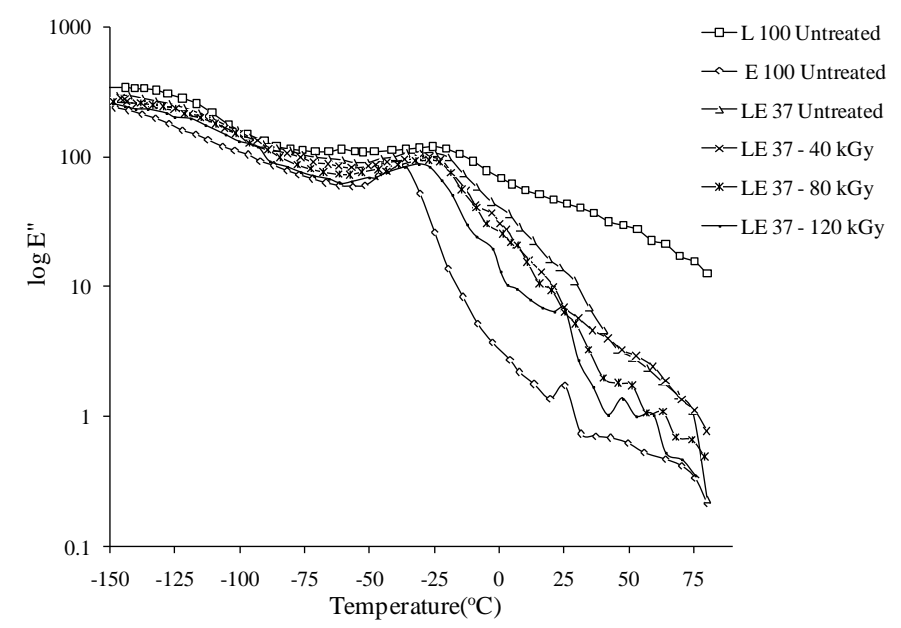

(b)

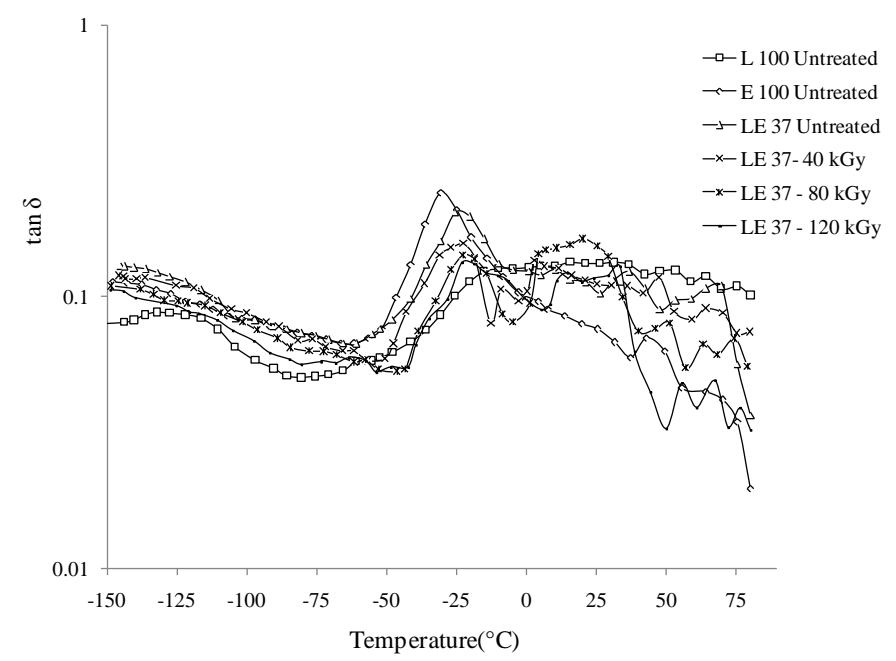

(c)

Figure 7. Variation in dynamic mechanical properties of LE37 blends with temperature and radiation dose (a) variation in storage modulus (b) variation in loss modulus (c) variation in $\tan \delta$. 
Table 2. Storage modulus (E'), loss modulus (E”) and transition temperature of neat LDPE, neat EPDM and their blends before and after electron beam irradiation.

\begin{tabular}{|c|c|c|c|c|c|c|c|c|}
\hline Samples & $\begin{array}{c}\mathrm{E}^{\prime} \\
\left(-140^{\circ} \mathrm{C}\right) \\
(\mathrm{MPa})\end{array}$ & $\begin{array}{c}\mathrm{E}^{\prime} \\
\left(-75^{\circ} \mathrm{C}\right) \\
(\mathrm{MPa})\end{array}$ & $\begin{array}{c}\mathrm{E}^{\prime} \\
\left(+25^{\circ} \mathrm{C}\right) \\
(\mathrm{MPa})\end{array}$ & $\begin{array}{c}\mathrm{E}^{\prime \prime} \\
\left(-140^{\circ} \mathrm{C}\right) \\
(\mathrm{MPa})\end{array}$ & $\begin{array}{c}\mathrm{E} ” \\
\left(-75^{\circ} \mathrm{C}\right) \\
(\mathrm{MPa})\end{array}$ & $\begin{array}{c}\mathrm{E} ” \\
\left(+25^{\circ} \mathrm{C}\right) \\
(\mathrm{MPa})\end{array}$ & $\begin{array}{c}\text { Temp. } \\
\text { corresponding } \\
\text { to } \tan \delta_{\max }(\mathrm{LDPE})\end{array}$ & $\begin{array}{c}\text { Temp. } \\
\text { corresponding to } \\
\tan \delta_{\max }(\mathrm{EPDM})\end{array}$ \\
\hline L100 & 3780 & 2120 & 327 & 374 & 150 & 54 & $\begin{array}{l}-132 \\
-15\end{array}$ & - \\
\hline E100 & 1720 & 926 & 9 & 227 & 73 & 2 & - & -30 \\
\hline LE 73 & 2570 & 1610 & 197 & 339 & 129 & 55 & -130 & \\
\hline LE 7340 kGy & 3130 & 1820 & 240 & 330 & 115 & 31 & $\begin{array}{l}-15.4 \\
-132\end{array}$ & \\
\hline LE 7380 kGy & 3320 & 1910 & 215 & 315 & 109 & 24 & $\begin{array}{l}-15.2 \\
-131\end{array}$ & \\
\hline LE 73120 kGy & 3600 & 2030 & 340 & 290 & 94 & 22 & $\begin{array}{l}-15.2 \\
-134 \\
-14.9\end{array}$ & \\
\hline LE 55 & 2350 & 1345 & 62 & 314 & 109 & 11 & -128 & -23.6 \\
\hline LE 5540 kGy & 2460 & 1552 & 141 & 282 & 96 & 10 & -127.8 & -33.2 \\
\hline LE 5580 kGy & 2530 & 1665 & 176 & 290 & 92 & 8 & -129.7 & -29.9 \\
\hline LE 55120 kGy & 2860 & 1820 & 224 & 262 & 78 & 13 & -127.3 & -32.1 \\
\hline LE 37 & 2096 & 1196 & 18 & 294 & 104 & 9 & -129 & -25 \\
\hline LE 3740 kGy & 2230 & 1230 & 69 & 255 & 97 & 7 & -128 & -22.5 \\
\hline LE 3780 kGy & 2425 & 1293 & 108 & 259 & 84 & 5 & -129 & -22.3 \\
\hline LE 37120 kGy & 2700 & 1480 & 180 & 234 & 76 & 7 & -129 & -22.1 \\
\hline
\end{tabular}

radiation, degree of crosslinking depending on irradiation dose and blend composition. This three dimensional interchain crosslinked network makes the materials stiffer and rigid, which provide greater resistance to dynamic deformation. That's why irradiation leads to increase in storage modulus in the whole range of temperature studied degree depending on irradiation doses. All crosslinked samples show reduced storage moduli with temperature due to same reason as unirradiated, i.e. increase in chain mobility at high temperature.

Loss modulus measures the energy dissipated as heat, representing the viscous portion.

Neat LDPE shows multiple loss peaks in temperature range $-140^{\circ} \mathrm{C}$ to $80^{\circ} \mathrm{C}$, from $374 \mathrm{MPa}$, the loss modulus reduces to $150 \mathrm{MPa}$ at $-75^{\circ} \mathrm{C}$, which again reduces to $54 \mathrm{MPa}$ at $25^{\circ} \mathrm{C}$ (Figure $4(\mathrm{~b})$ ). On the other hand, the loss modulus of EPDM reduces drastically from 227 to $73 \mathrm{MPa}$ while temperature increases from $-140^{\circ} \mathrm{C}$ to $-75^{\circ} \mathrm{C}$. This value again goes down to $2 \mathrm{MPa}$ at $25^{\circ} \mathrm{C}$. This drastic reduction is due to rubbery nature of the polymer. The blends lie in between LDPE and EPDM in loss modulus vs. temperature sweep graph. Like storage modulus, loss modulus also increases with increase in LDPE content in the blends. This observation is very similar with the reported literature on the DMA study of LLDPE/PDMS blends [27]. All blends follow similar trend in changing loss modulus with temperatures, which are very similar to two neat polymers (Figure 4(b)).

It is seen that at $-140^{\circ} \mathrm{C}$ loss modulus (E”) of blends (LE73, LE55 and LE37) reduces to with increase of radiation doses (40 to 120 kGy, Figure 5(b), Figure 6(b), Figure 7(b) and Table 2). Similar trend of decrease of loss modulus of all above blends are also noticed at $-75^{\circ} \mathrm{C}$ and $25^{\circ} \mathrm{C}$ (Table 2). Higher degree of crosslinking introduces higher degree of elasticity in blends. An elastic system would dissipate less energy as heat [28]. So after crosslinking, loss is less. The ratio of loss modulus to storage modulus is referred as internal damping or loss tangent $(\tan \delta)$. It tells us how good a material will be at absorbing energy. It is a measurement of how well a material can get rid of energy and it is reported as the tangent of the phase angle. The changes of loss tangents with temperature for all samples are represented in Figure 4(c). The temperature corresponding to $\tan \delta_{\max }$ is 
considered as glass transition temperature (Tg). All Tg values are reported in Table 2.

From Figure 4(c), it is obvious that in the whole temperature range $\tan \delta$ (internal damping) of EPDM is more than LDPE due to the flexible rubbery nature of the former. All blends exhibit higher $\tan \delta$ value (internal damping) than both LDPE and EPDM in lower temperature range (approximately $-150^{\circ} \mathrm{C}$ to $-50^{\circ} \mathrm{C}$ ). It is very unique that, at the lower temperature range, $\tan \delta$ of LE73 and LE55 are higher than LE37. This synergism occurs due to combined effect of segmental motion of LDPE chains in the glass transition region ( $\mathrm{Tg}$ is around $-132^{\circ} \mathrm{C}$ ) and flexibility of amorphous chain of EPDM. The $\tan \delta_{\max }$ value for EPDM is 0.292 , which again reduces to 0.21 for LE 37 sample with a strong peak at the same position. The $\tan \delta_{\max }$ for LE55 again becomes 0.18. Thus, the reduction of EPDM content in blend decreases the peak height of $\tan \delta_{\max }$ indicating lower damping property of blend around glass transition region of EPDM. Generally, LDPE exhibits three different relaxation peaks, $\alpha, \beta$ and $\gamma$ where $\alpha$ peak occurs at the highest temperature around $80^{\circ} \mathrm{C}, \beta$ and $\gamma$ peak occur at $-15^{\circ} \mathrm{C}$ and $-132^{\circ} \mathrm{C}$ respectively. As our samples are run up to $80^{\circ} \mathrm{C}$, thus $\beta$ and $\gamma$ appear prominently in our case. Accordingly to Takayangi, the $\gamma$ relaxation is due to relaxation of $-\mathrm{CH}_{2}$ units in the amorphous region and molecular mechanism is same as the $\alpha$ relaxation, which is associated with $-\mathrm{CH}_{2}$ unit for crystalline region. This is considered as Tg (glass transition temperature) [29]. $\beta$-relaxation is associated with side branching of polyethylene. Oakes and Rabinson interpret the $\beta$ peak in LDPE as being due to the relaxation of branch point containing the side $-\mathrm{R}$ [30]. $\beta$ peak seems to be a combination of more than one transition [31]. On the other hand, Tg (temperature corresponding to $\tan \delta_{\max }$ ) for EPDM appears with a prominent intense peak at $-30^{\circ} \mathrm{C}$. But for all three blends (LE73, LE55 and LE37) transition corresponding to Tg of LDPE does not appear recognizable. It is reported that Tg of LDPE is masked due to interaction between blend components [32] [33]. If the slope changing points are considered as Tg of LDPE, then the values for LE73, LE55 and LE37 will be reported as $-130^{\circ} \mathrm{C},-128^{\circ} \mathrm{C}$ and $-129^{\circ} \mathrm{C}$ respectively. Again, due to overlapping of $\beta$ relaxation zone of LDPE and Tg of EPDM a wide peak in LE73 appears at $-15.4^{\circ} \mathrm{C}$ due to higher amount of LDPE in blend (Table 2).

In LE55, a prominent peak, corresponding to Tg of EPDM occurs at $-23.6^{\circ} \mathrm{C}$. For LE 37, that peak appears at $-25^{\circ} \mathrm{C}$ but with less peak height and peak area than those of pure EPDM. From these observations it reveals that LDPE/EPDM blends are partially compatible as the Tg of EPDM is increasing depending on LDPE content [34].

On crosslinking all three blends LE73, LE55 and LE 37 show almost similar behavior in changing damping property with irradiation dose and temperature (Figure 5(c), Figure 6(c), Figure 7(c). and Table 2). For all blends, damping property $(\tan \delta)$ values keep on decreasing with irradiation dose in whole range of temperature. For all blends transition peak heights are also reduced upon crosslinking depending on radiation dose. Damping property is reduced due to restricted molecular mobility in crosslinked network.

For crosslinked LE73 transition occurs around $-130^{\circ} \mathrm{C}$ and $-15^{\circ} \mathrm{C}$ like uncrosslinked one. Both are due to LDPE. Second transition merges with the glass transition of EPDM $\left(-30^{\circ} \mathrm{C}\right)$. Due to higher quantity of LDPE in blends $\beta$ transition dominates in LE73 blends masking the glass transition of EPDM. After crosslinking there is no change of transition temperatures (Table 2).

$\gamma$ transition $\left(-130^{\circ} \mathrm{C}\right.$, Tgs of LDPE) in LE55 and LE 37 does not change much after crosslinking, though in blends there is no sharp peak of LDPE before and after crosslinking.

In LE 55, the transition at $-23.6^{\circ} \mathrm{C}$ (ascribed to Tg of EPDM), shifts towards lower temperature on crosslinking at 40, 80 and $120 \mathrm{kGy}$. This may be due to higher intraphase crosslinking than interphase crosslinking in blend, which reduces the compatibility. The second peak of LDPE $\left(-15^{\circ} \mathrm{C}\right)$ is merged with this peak. In LE 37 , second transition occurs at $-25^{\circ} \mathrm{C}$, which remains almost unchanged after crosslinking at all three doses.

Morphologies of fractured surfaces of unirradiated and irradiated LE 73, LE 55 and LE 37 blends are investigated by SEM and pictures are provided in Figures 8(a)-(f). In LE 73 blend, the fractured cracks and fissures can be seen across the coarse surface where small domains are dispersed in matrix indicating less ductile surface of blend (Figure 8(a)). Surface of LE 37 may be considered as a more ductile fracture in which matrix yielding is considerably high (a higher degree of plastic deformation) (Figure 8(b)). Such kind of morphology may also be considered as ball and socket type structure, where cavity behaves like a socket and other phase is like ball. These sockets are continuous phase in which dispersed domains are balls [35]. This is the typical characteristics of ductile surfaces. In LE37, EPDM, being higher in amount, becomes matrix and LDPE is the dispersed phase [36] (Figure 8(b)).

In LE 55 untreated, both components are in same proportions and the fractured surface looks like honeycomb 


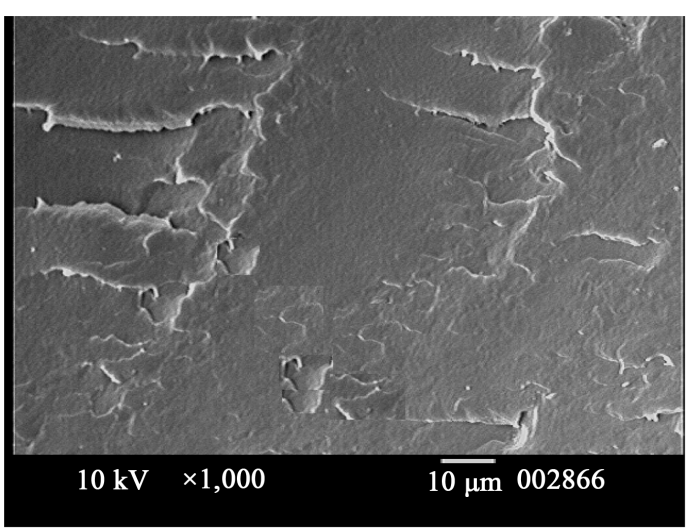

(a)

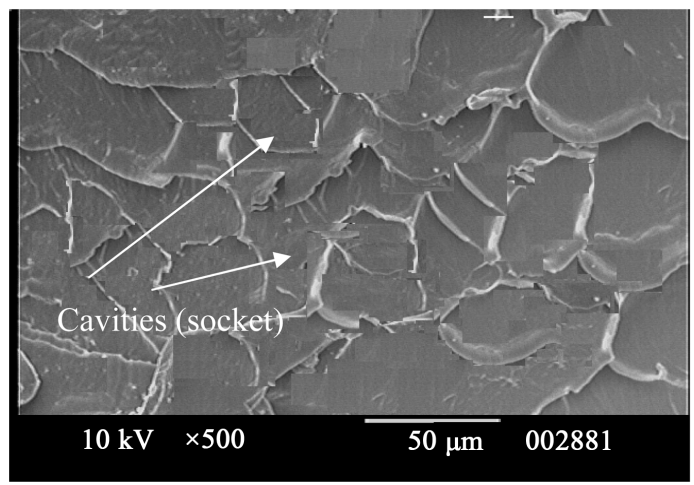

(c)

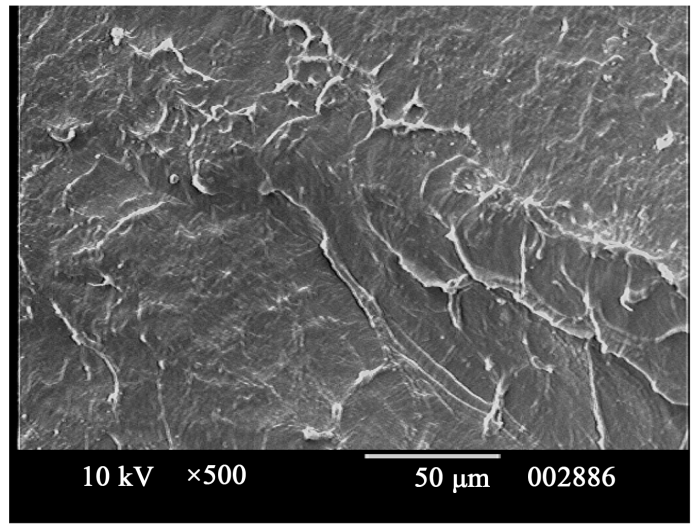

(e)

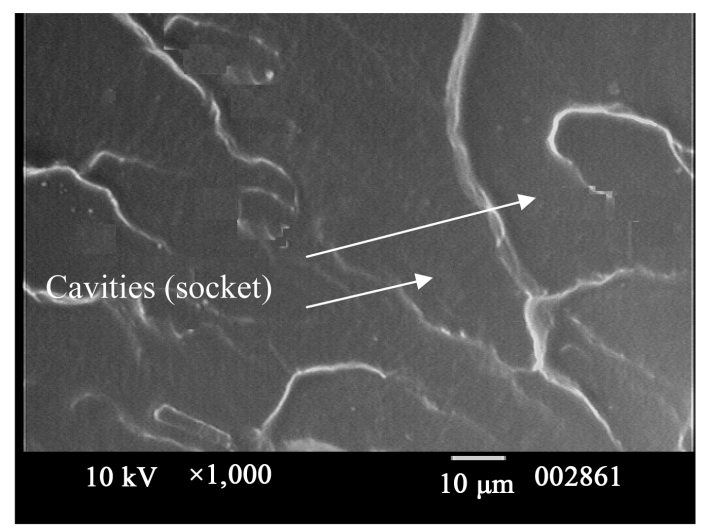

(b)

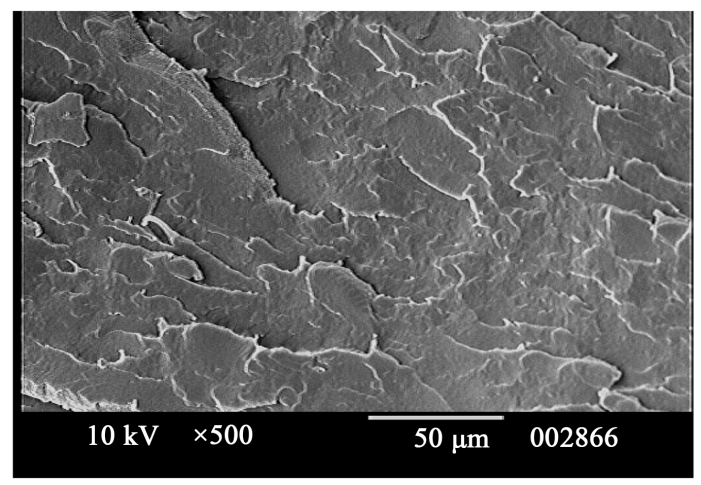

(d)

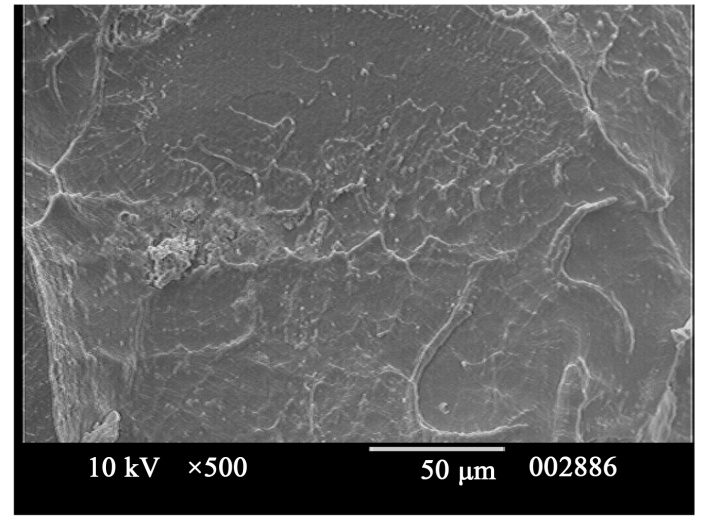

(f)

Figure 8. SEM image of fracture surfaces: (a) LE 73 untreated; (b) LE 37 untreated; (c) LE 55 untreated; (d) LE 55 - 40 kGy; (e) LE 55 - 80 kGy; (f) LE 55 - 120 kGy.

(Figure 8(c)). Significant interface interaction between plastic and elastomer phase, composition and flow behavior are responsible for this kind of organized symmetrical morphology. Symmetrical cavities (i.e. sockets) can be noticed across the fracture surface, which shows high degree of ductility. This type of honeycomb-like structure indicates the considerable degree of miscibility between thermoplastic and elastomer. Due to equal amount of LDPE and EPDM the miscibility is higher, which generates the above mentioned structures. Thus the increase in damping properties and decrease in storage modulus with increasing EPDM content can be understand now by the above discussed morphologies. Moreover, it is noticed that with increasing EPDM content in the blends (Figures 8(a)-(c)) the morphology changes from spherical to co-continuous structure, which again supports the change in storage modulus and damping property with change in blend compositions. 
However, these organized structures were destructed and surface becomes smoother with disappearance of roughness after irradiation with different doses. The size of cavities continues to reduce with radiation doses. It is seen from the Figures 8 (c)-(f) that surface becomes smoother with increase in irradiation dose.

At $40 \mathrm{kGy}$, the size and depth of cavities of LE55 get reduced and large number of flow patches are generated across the surface and surface starts to become smoother (Figure 8(d)). Again, at $80 \mathrm{kGy}$, surface becomes relatively smoother with further reduction of cavity sizes and depth with shorter flow patches (Figure 8(e)). At 120 $\mathrm{kGy}$, surface features alter in the same direction introducing more smoothness. These changes occur mainly due to the presence of micro radicals generated by irradiation. These micro radicals react at the boundary surface of the different phases and consequently the adhesion between two phases due to inter chain and intra chain is increased and more uniform surfaces are produced [37]. This appearance resembles with stiffer surfaces. That is the reason why with increases in radiation doses, storage modus becomes higher and higher and damping becomes lower and lower [38].

\section{Conclusion}

From the increase in percentage gel of LDPE and EPDM and their blends with increased radiation dose, it is seen that the crosslinking efficiency of EPDM is higher than LDPE. The trend of change of storage modulus with blend composition before and after irradiation is similar (higher the EPDM content less is the modulus), only the values are higher for irradiated samples that keeps on increasing with dose. On irradiation loss modulus continues to decrease with dose for a particular blend. For EPDM rich blend the damping properties is found higher though at lower temperature range LDPE rich blend shows greater damping properties due to synergism of glass transition of LDPE and vibration of amorphous EPDM chains. Upon irradiation damping properties keep on decreasing with dose. EPDM rich blends show more ductile surface with higher matrix yielding, supporting less storage modulus. But irradiation makes surface smooth and smoothness keeps on increasing with irradiation dose revealing increased compatibility (higher stiffness) between two phases through crosslinking.

\section{References}

[1] Brydson, J.A. (1996) Plastics Materials. 6th Edition, Butterworth-Heinemann, Oxford.

[2] Freakley, P.K. (1985) Rubber Processing and Production. Plenum Press, New York. http://dx.doi.org/10.1007/978-1-4613-2375-4

[3] Sen-Majumder, P. and Bhowmick, A.K. (2000) Structure-Property Relationship of Electron-Beam-Modified EPDM Rubber. Journal of Applied Polymer Science, 77, 323-337. http://dx.doi.org/10.1002/(SICI)1097-4628(20000711)77:2<323::AID-APP8>3.0.CO;2-V

[4] Singh, A. (2001) Irradiation of Polymer Blends Containing a Polyolefin. Radiation Physics and Chemistry, 60, 453459. http://dx.doi.org/10.1016/S0969-806X(00)00418-7

[5] Airinei, A. (2013) Structural Characteristics of Some High Density Polyethylene/EPDM Blends. Polymer Testing, 32, 187-196. http://dx.doi.org/10.1016/j.polymertesting.2012.10.010

[6] Ehsani, M., Zeynali, M.E., Abtahi, M. and Harati, A.A. (2009) LDPE/EPDM blends as Electrical Insulators with Unique Surface, Electrical and Mechanical Properties. Iranian Polymer Journal, 18, 37-47.

[7] Senna, M.M., Youssef, H.A. and Eyssa, H.M. (2007) Effect of Electron Beam Irradiation, EPDM and Azodicarbonamide on the Foam Properties of LDPE Sheet. Polymer-Plastics Technology and Engineering, 46, 1093-1101. http://dx.doi.org/10.1080/03602550701525271

[8] Sadek, E.M., El-Nashar, D.E. and Motawie, A.M. (2003) Modification of Ethylene Propylene Diene Terpolymer Rubber by Some Thermoplastic Polymers. Polymer-Plastics Technology and Engineering, 42, 627-642. http://dx.doi.org/10.1081/PPT-120023099

[9] Kim, D.H. and Kim, S.C. (1989) Effects of Curing Conditions on the Properties of the Dynamically Cured EPDM/ HDPE Blends. Polymer Bulletin, 21, 401-408. http://dx.doi.org/10.1007/BF01045176

[10] Nouri, M. and Mehrabzadeh, M. (1996) Studies on Rheological Behaviour of LDPE/EPDM Blends Using a Torque Rheometer. Iranian Polymer Journal, 5, 237-241.

[11] Choudhury, A. and Adhikari, B. (2007) Dynamic Vulcanization of Recycled Milk Pouches (LDPE-LLDPE) and EPDM Blends Using Dicumyl Peroxide. Polymer International, 56, 1213-1223. http://dx.doi.org/10.1002/pi.2262

[12] Abdel-Aziz, M.M., Abdel-Bary, E.M., Abou Zaid, M.M. and El Miligy, A.A. (1992) Effect of Gamma Radiation on EPDM/LDPE Blends. Journal of Elastomers and Plastics, 24, 178-191. 
http://dx.doi.org/10.1177/009524439202400303

[13] Nouri, M. and Mehrabzadeh, M. (1996) Studies on Rheological Behavior of LDPE/EPDM Blends Using a Torque Rheometer. Iranian Polymer Journal, 5, 237-241.

[14] Jamal, N.A., Anuar, H. and Raza, S.B.A. (2011) Modification of Tensile and Impact Properties of Crosslinked Rubber Toughened Nanocomposites via Electron Beam Irradiation. Canadian Journal on Scientific \& Industrial Research, 2, 133-142.

[15] Shin, B.-S., Seo, D.-K., Kim, H.-B., Jeun, J.-P. and Kang, P.-H. (2012) A Study of the Thermal and Mechanical Properties of Electron Beam Irradiated HDPE/EPDM Blends in the Presence of Triallyl Cyanurate. Journal of Industrial and Engineering Chemistry, 18, 526-531. http://dx.doi.org/10.1016/j.jiec.2011.11.025

[16] Avitzur, B. (1997) Electron Beam Crosslink Irradiation of Wire and Cable Insulation, Technical Report. Proceedings of the 47th Annual Convention of the Wire Association International, Boston, 17 October 1997.

[17] Naskar, K., Gohs, U., Heinrich, G. and Wagenknecht, U. (2009) PP-EPDM Thermoplastic Vulcanisates (TPVs) by Electron Induced Reactive Processing. Express Polymer Letters, 3, 677-683.

http://dx.doi.org/10.3144/expresspolymlett.2009.85

[18] Clegg, D.W. and Collyer, A.A. (1991) Hand Book of Irradiation Effects on Polymers. Elsevier, New York.

[19] McGinnis, V.D. (1986) Encyclopedia of Polymer Science and Technology. John Wiley \& Sons, New York, 445.

[20] Chowdhury, S.R., Sabharwal, S. and Sarma, K. (2012) Development of Recyclable Electron Beam Radiation Crosslinked LDPE/EVA-Embedded Nanoclay Nanocomposites. Journal of Reinforced Plastics and Composites, 31, 14261434. http://dx.doi.org/10.1177/0731684412459247

[21] Charlesby, A. (1954) Gel Formation and Molecular Weight Distribution in Long Chain Polymers. Proceedings of the Royal Society A, 222, 542-557. http://dx.doi.org/10.1098/rspa.1954.0094

[22] Charlesby, A. and Pinner, S.H. (1959) Analysis of the Solubility of Irradiated Polyethylene and Other Polymers. Proceedings of the Royal Society A, 249, 367-386. http://dx.doi.org/10.1098/rspa.1959.0030

[23] Dikland, H.G. and Van Duin, M. (2002) Crosslinking of EPDM Studied with Optical Spectroscopy. In: Litvinov, V.M. and De, P.P., Eds., Spectroscopy of Rubber and Rubbery Materials, Rapra Tech Ltd., Shawbury, 656.

[24] Chowdhury, R. and Banerji, M.S. (2005) Electron Beam Irradiation of Ethylene-Propylene Terpolymer: Evaluation of Trimethylol Propane Trimethacrylate as a Crosslink Promoter. Journal of Applied Polymer Science, 97, 968-975. http://dx.doi.org/10.1002/app.21795

[25] Zaharescu, T., Feraru, E., Podina, C. and Jipa, S. (2005) High Energy Radiation Processing of EPDM in a Hydrocarbon Environment. Part 1. Methylcyclopentane. Polymer Degradation and Stability, 89, 373-381.

[26] Chowdhury, S.R. (2008) Some Important Aspects in Designing High Molecular Weight Poly(L-lactic acid)-Clay Nanocomposites with Desired Properties. Polymer International, 57, 1326-1332. http://dx.doi.org/10.1002/pi.2464

[27] Giri, R., Naskar, K. and Nando, G.B. (2012) Effect of Electron Beam Irradiation on Dynamic Mechanical, Thermal and Morphological Properties of LLDPE and PDMS Rubber Blends. Radiation Physics and Chemistry, 81, 1930-1942. http://dx.doi.org/10.1016/j.radphyschem.2012.08.004

[28] Nielsen, L.E. (1962) Mechanical Properties of Polymers. Reinhold Publishing Corp, New York, 150.

[29] Takayanagi, M., Uemura, S. and Minami, S. (1964) Application of Equivalent Model Method to Dynamic Rheo-Optical Properties of Crystalline Polymer. Journal of Polymer Science Part C: Polymer Symposia, 5, 113-122. http://dx.doi.org/10.1002/polc.5070050111

[30] Oakes, W.G. and Rabinson, D.W. (1954) Dynamic Electrical and Mechanical Properties of Polythene over a Wide Temperature Range. Journal of Polymer Science, 14, 505-507. http://dx.doi.org/10.1002/pol.1954.120147712

[31] Ray, I. and Khastigir, D. (1993) Correlation between Morphology with Dynamic Mechanical, Thermal, Physicomechanical Properties and Electrical Conductivity for EVA-LDPE Blends. Polymer, 34, 2030-2037. http://dx.doi.org/10.1016/0032-3861(93)90727-R

[32] Koleske, J.V. and Lundberg, R.D. (1969) Lactone Polymers. I. Glass Transition Temperature of Poly-ع-Caprolactone by Means on Compatible Polymer Mixtures. Journal of Polymer Science Part A-2, 7, 795-807. http://dx.doi.org/10.1002/pol.1969.160070505

[33] Hickman, J.J. and Ikeda, R.M. (1973) Studies of Polymer Blends I. Compatibility of Poly(vinyl chloride) and Poly(ethylene-co-vinyl acetate-co-sulfur dioxide). Journal of Polymer Science Part A-2, 11, 1713-1721. http://dx.doi.org/10.1002/pol.1973.180110904

[34] Bhattacharyya, A.R., Ghosh, A.K. and Misra, A. (2001) Reactively Compatibilised Polymer Blends: A Case Study on PA6/EVA Blend System. Polymer, 42, 9143-9154. http://dx.doi.org/10.1016/S0032-3861(01)00390-1

[35] Okada, O., Keskkula, H. and Paul, D.R. (2000) Fracture Toughness of Nylon 6 Blends with Maleated Ethylene/Propylene 
Rubbers. Polymer, 41, 8061-8074. http://dx.doi.org/10.1016/S0032-3861(00)00163-4

[36] Mukhopadhyay, P. and Das, C.D. (1990) Effect of E/P Ratio on the Rheology and Morphology of Crosslinkable Polyethylene and EPDM Blends. Journal of Applied Polymer Science, 39, 49-62. http://dx.doi.org/10.1002/app.1990.070390105

[37] Senna, M.M.H., Abdel-Moneam, Y.K., Hussein, Y.A. and Alarifi, A. (2012) Effects of Electron Beam Irradiation on the Structure-Property Behavior of Blends Based on Low-Density Polyethylene and Styrene-Ethylene-Butylene-StyreneBlock Copolymers. Journal of Applied Polymer Science, 125, 2384-2393. http://dx.doi.org/10.1002/app.36488

[38] Sengupta, R., Sabharwal, S., Tikku, V.K., Somani, A.K., Chaki, T.K. and Bhowmick, A.K. (2006) Effect of AmbientTemperature and High-Temperature Electron-Beam Radiation on the Structural, Thermal, Mechanical, and Dynamic Mechanical Properties of Injection-Molded Polyamide-6,6. Journal of Applied Polymer Science, 99, 1633-1644.

http://dx.doi.org/10.1002/app.22689 